\title{
DO MULCHED PRUNINGS POSE A DISEASE RISK FOR GRAPES?
}

\author{
D.C. MUNDY and R.H. AGNEW \\ The Horticulture and Food Research Institute of New Zealand, \\ Private Bag 1007, Blenheim \\ Corresponding author: dmundy@hortresearch.co.nz.
}

In Marlborough, HortResearch are investigating the utilisation of organic wastes for horticultural production as a means of waste management. Field trials were established in January 1999 to investigate the use of mulches containing organic wastes, including vineyard prunings. Local grape growers expressed reservations about the use of mulches containing prunings, as they perceived the mulch to be a source of Botrytis inoculum. Botrytis bunch rot (caused by Botrytis cinerea) can cause large reductions in the value of grapes grown for wine production. Experiments were conducted to measure the levels of Botrytis inoculum produced by the mulch over time. During the period April 1999 March 2001, 10 Botrytis recovery experiments were conducted. Only 1 of the 640 mulch samples collected during this period resulted in the recovery of Botrytis cinerea. In addition to the mulch sampling, bunch rot levels of vines grown above the mulch and in adjacent non mulched plots were assessed during the 1999/00 and 2000/01 seasons. From this research it was concluded that use of grapevine prunings for under vine mulches does not increase the incidence of Botrytis bunch rot under Marlborough conditions. Investigations are under way to determine whether mulching offers any benefits to vine health.

\section{SCANNING ELECTRON MICROSCOPY OF LEAF SURFACES OF GREENHOUSE GROWN VEGETABLES}

\author{
H. KRISHNA and A. CARPENTER \\ Crop \& Food Research, Private Bag 11 600, Palmerston North \\ Corresponding author: krishnah@crop.cri.nz
}

The use of spray additives to enhance the activity of pesticides is a common practice among greenhouse vegetable crop growers. There is a general belief amongst growers that spray additives should be added to the spray solution to increase biological activity of active ingredients. Additives generally lower surface tension and, more importantly, aid in the penetration of epicuticular waxes that cover the foliage being treated. Epicuticular waxes on foliage on plants grown outdoors are generally denser that those grown in protected environments like the greenhouse. This study investigated the leaf surfaces of the important greenhouse grown crops, tomato, capsicum, cucumber, aubergine and beans, using cryo-scanning electron microscopy. Epicuticular waxes covering foliage were found to be scant in greenhouse grown crops compared to field grown plants like clover. This information can be used to justify the use of spray additives for cost effective management of pests and diseases in greenhouse vegetables. 